\title{
KONDISI PADANG LAMUN DI PULAU PANJANG DAN PULAU LIMA, BANTEN
}

\section{CONDITIONS OF SEAGRASS IN PANJANG ISLAND AND LIMA ISLAND, BANTEN}

\author{
Rafdi Abdillah Harjuna, Ita Riniatsih*, Chrisna Adhi Suryono \\ Departemen IImu Kelautan, Fakultas Perikanan dan Ilmu Kelautan, Universitas Diponegoro \\ Jl. Prof. H. Soedarto S.H, Tembalang, Semarang, Jawa Tengah 50275 Indonesia \\ Email: iriniatsih@yahoo.com
}

\begin{abstract}
ABSTRAK
Ekosistem padang lamun merupakan salah satu ekosistem laut dangkal yang memiliki fungsi ekologis yang penting dalam menjaga kelestarian keanekaragaman hayati. Ekosistem yang ada di perairan laut dangkal, padang lamun di Indonesia belum banyak diketahui dan bahkan hampir tidak diperhatikan, namun ekosistem ini mempunyai berbagai fungsi penting di perairan laut dangkal. Status kesehatan ekosistem padang lamun dapat ditentukan berdasarkan nilai penutupan (\%). Ekosistem padang lamun memiliki beberapa faktor lingkungan yang mempengaruhi seperti suhu, salinitias, $\mathrm{pH}$, kecepatan arus, kedalaman dan komposisi sedimen. Penelitian ini bertujuan untuk mengidentifikasi dan mengetahui penutupan lamun (\%) dan faktor-faktor yang mempengaruhinya di Pulau Panjang dan Pulau Lima, Banten. Penelitian ini dilakukan pada bulan Oktober 2019 dengan menggunakan metode deskriptif dan purposive sampling dalam penentuan lokasinya. Identifikasi dan pengambilan data lamun mengacu pada metode LIPI. Lamun yang ditemukan yaitu Enhalus acoroides dan Thalassia hemprichii dengan nilai penutupan (\%) pada Pulau Panjang $(11,55-12,5 \%)$ dan Pulau Lima (14,21-15,34\%). Faktor lingkungan lainnya nilai optimum bagi pertumbuhan lamun yaitu nilai suhu dan kecepatan arus dan dengan ditemukannya jenis komposisi sedimen yaitu pasir dan pasir berlumpur.
\end{abstract}

Kata kunci: Lamun, Tutupan, Sedimen, Banten

\begin{abstract}
Seagrass are one of the marine ecosystems that have an important ecological function in maintaining biodiversity. The ecosystems that exist in shallow sea waters, seagrass meadows in Indonesia are not widely known and even almost ignored, but this ecosystem has various important functions in marine ecosystem. The health status of the seagrass ecosystem can be determined based on the percent cover $(\%)$. Seagrass have several environmental factors that influence such as temperature, salinity, $\mathrm{pH}$, current velocity, depth and sediment composition. This study aims to identify and monitor seagrass percent cover and the factors that influence it in Pulau Panjang and Pulau Lima, Banten. This research was conducted in October 2019 using descriptive methods and purposive sampling in determining the location. Seagrass identification and data collection refers to the LIPI method. There were 2 types of seagrass found, namely Enhalus acoroides and Thalassia hemprichii with a percent cover on Pulau Panjang (11.55-12.5\%) and Pulau Lima (14.21-15.34\%). Other environmental factors that are outside the optimal value for seagrass growth, namely the value of temperature and sea current and the discovery of the type of sediment composition, namely sand and silty sand.
\end{abstract}

Keywords: Seagrass, Percent Cover, Sediment, Banten

\section{PENDAHULUAN}

Perairan Pulau Panjang dan Pulau Lima termasuk perairan yang terdapat banyak aktivitas manusia seperti kegiatan industri, budidaya perikanan dan kegiatan wisata bahari. Perairan Pulau Panjang dan Pulau Lima termasuk dalam perairan laut dangkal yaitu menurut (Supriyadi et al., 2018), ekosistem perairan laut dangkal yaitu sebagai ekosistem yang memiliki kelimpahan keanekaragaman sumberdaya hayati yang tinggi. Menurut 
Tangke (2010), ekosistem padang lamun merupakan salah satu ekosistem yang belum banyak diketahui bahkan hampir tidak diperhatikan. Selain itu, ekosistem padang lamun merupakan salah satu ekosistem perairan laut yang mempunyai produktivitas primer yang tinggi, yang memiliki peranan penting untuk menjaga kelestarian keanekaragaman organisme laut (Riniatsih, 2016). Fungsi ekologis padang lamun diantaranya adalah sebagai daerah pemijahan (spawning ground), daerah asuhan (nursery ground), daerah mencari makan (feeding ground), produsen primer, penangkap sedimen, dan sebagainya. Status kesehatan padang lamun dapat ditentukan berdasarkan nilai penutupan lamun (\%) dengan kategori kaya / sehat: $\geq 60$; kurang kaya / kurang sehat: 30-59,9 dan miskin: $\leq 29,9$ (Keputusan Menteri Lingkungan Hidup No. 200 Tahun 2004). Padang lamun dapat dipengaruhi tumbuh dan berkembang oleh beberapa faktor lingkungan seperti suhu, salinitas, derajat keasaman $(\mathrm{pH})$, kecepatan arus, kedalaman dan komposisi sedimen (Herkul dan Kotta, 2009). Padang lamun dapat membentuk berupa satu jenis lamun (monospecific) atau lebih dari satu jenis (multispecific) yang hidup pada daerah pasang surut, tempat hidupnya dapat berupa lumpur, pasir dan karang mati sehingga salah satu faktor lingkungannya yaitu komposisi sedimennya (Latuconsina, 2012). Untuk itu perlu dilakukan penelitian ini dengan tujuan mengidentifikasi dan mengetahui nilai prosentase penutupan lamun untuk mengetahui status kesehatannya serta mengkaji beberapa faktor lingkungan yang mempengaruhi ekosistem padang lamun di Pulau Panjang dan Pulau Lima, Teluk Banten.

\section{MATERI DAN METODE}

Penelitian ini dilaksanakan pada bulan Oktober 2019 di perairan Pulau Panjang dan Pulau Lima, Teluk Banten. Materi yang digunakan dalam penelitian ini adalah lamun untuk identifikasi dan persentase penutupannya, sampel sedimen untuk analisa ukuran butir, serta parameter perairan lainnya, seperti suhu, salinitas, derajat keasaman $(\mathrm{pH})$, kecepatan arus dan kedalaman. Metode penelitian ini menggunakan metode deskriptif yaitu menjelaskan secara luas keadaan suatu lokasi yang sesuai dengan keadaan di lapangan dan yang mempengaruhinya (Aryawati et al., 2018). Penentuan lokasi penelitian menggunakan metode purposive sampling yaitu penentuan atau pengambilan sampel dengan sengaja berdasarkan pertimbangan dan tujuan tertentu (Riniatsih, 2015).

Penentuan lokasi dan pengambilan data lamun di kedua pulau ditentukan masingmasing 2 stasiun. Pada masing-masing stasiun terdapat 3 garis transek dengan berjarak $50 \mathrm{~m}$ untuk masing-masing garis transek dengan panjang $100 \mathrm{~m}$ tegak lurus dengan pantai ke arah laut. Lokasi penelitian dapat dijelaskan dengan kode stasiun dan koordinat masingmasing stasiun yaitu Stasiun 1 Pulau Panjang (B.PJG.01) - S $5^{\circ} 56.435^{\prime}$ E $106^{\circ} 08.558^{\prime}$ dan Stasiun 2 Pulau Panjang (B.PJG.02) - S 50 55.265' E $106^{\circ} 09.552^{\prime}$. Stasiun 1 Pulau Lima (B.LM.01) - S $6^{\circ} 00.081^{\prime}$ E $106^{\circ} 09.169^{\prime}$ dan Stasiun 2 Pulau Lima (B.LM.02) - S $6^{\circ} 00.011^{\prime}$ E $106^{\circ}$ 09.196'. Penghitungan estimasi prosentase penutupan lamun dilakukan dengan bantuan kuadran yang terbuat dari pipa PVC dengan ukuran $50 \times 50 \mathrm{~cm}$ yang diletakkan dengan jarak $10 \mathrm{~m}$ di sebelah kanan sepanjang garis transek lamun, sehingga masing-masing garis transek terhitung sebanyak 11 kuadrat (Rahmawati et al., 2014). Data parameter perairan diambil secara in situ bersamaan dengan pengambilan data prosentase penutupan lamun untuk masingmasing stasiun. Selain pengambilan data pengukuran parameter perairan, juga dilakukan pengambilan sampel sedimen bersamaan dengan pengambilan data prosentase penutupan lamun dari masingmasing garis transek pada titik ke-5 dengan menggunakan sediment core dari pipa PVC diameter $15 \mathrm{~cm}$ yang dibenamkan pada sedimen hingga kedalaman $45 \mathrm{~cm}$. Sampel sedimen yang sudah diambil dimasukkan pada plastic ziplok berlabel, kemudian dimasukkan pada coldbox, untuk dilanjutkan analisa ukuran butir di Laboratorium Mekanika Tanah, Fakultas Teknik, Universitas Diponegoro. Menurut Saputra et al. (2013), untuk analisa ukuran butir dikarenakan yang dibutuhkan adalah ukuran butir maka dilakukan hingga tahap pengayakan dengan menggunakan sieve shaker dikarenakan yang dibutuhkan adalah ukuran butir maka hanya dilakukan hingga tahap pengayakan sedimen.

\section{HASIL DAN PEMBAHASAN}

Hasil dari Pulau Lima menunjukkan jenis lamun yang ditemukan adalah Enhalus acoroides dan Thalassia hemprichii dengan nilai penutupan lamun jenis Thalassia hemprichii berkisar 15,34 \% (Tabel 1), Enhalus acoroides 
yang ditemukan memiliki ciri khusus, diantaranya berukuran paling besar (Panjang daun mencapai 1 meter, lebar daun $1,5-2 \mathrm{~cm}$ ) dan terdapat serabut hitam yang menyerupai ijuk pada rhizoma Lamun kedua, spesies Thalassia hemprichii yang memiliki ciri khusus, diantaranya rhizoma beruas-ruas, ujung daun membulat dan terdapat garis / bercak coklat pada helaian daun.

Persentase penutupan lamun total di Pulau Panjang Stasiun 1 dan Stasiun 2 masing-masing adalah sebesar $11,55 \%$ dan $12,5 \%$ sedangkan di Pulau Lima Stasiun 1 dan Stasiun 2 masing-masing adalah sebesar $14,21 \%$ dan $15,34 \%$. Hasil penghitungan prosentase penutupan lamun di Pulau Panjang dan Pulau Lima termasuk dalam kategori miskin ( $\leq 29,9 \%$ ). Hasil pengambilan data lapangan menunjukkan terdapat 2 jenis lamun yang ditemukan yaitu Enhalus acoroides dan Thalassia hemprichii. Menurut Kiswara (1992) dan Chamidy et al. (2020), jenis lamun Enhalus acoroides dan Thalassia hemprichii ditemukan pada sedimen pasir berlumpur, kedua jenis lamun tersebut tumbuh dengan baik pada substrat dasar lumpur sampai pasir. Hal ini sesuai dengan hasil analisa ukuran butir yang menunjukkan bahwa dominansi jenis sedimen pasir halus dengan fraksi sand dan silt lebih tinggi dari fraksi gravel yang ditemukan di Pulau Panjang dan Pulau Lima.

Stasiun 1 Pulau Panjang hanya terdapat 1 jenis lamun yaitu Enhalus acoroides dengan nilai hasil analisa ukuran butir dapat dikategorikan bahwa di lokasi tersebut jenis sedimennya adalah pasir berlumpur yang termasuk dalam ukuran butir yang halus. Lokasi Stasiun 1 terletak di perairan yang dekat dengan terdapatnya ekosistem mangrove. Menurut penelitian Waycott et al. (2004), dapat menguatkan bahwa lamun jenis Enhalus acoroides mampu hidup diberbagai

Tabel 1. Nilai Penutupan Lamun (\%) di Pulau Panjang dan Pulau Lima

\begin{tabular}{cccccc}
\hline \multirow{2}{*}{ No. } & Jenis & \multicolumn{4}{c}{ Penutupan Lamun (\%) } \\
\cline { 3 - 6 } & & \multicolumn{2}{c}{ Pulau Panjang } & \multicolumn{2}{c}{ Pulau Lima } \\
\cline { 3 - 6 } & Stasiun 1 & Stasiun 2 & Stasiun 1 & Stasiun 2 \\
\hline \multirow{2}{*}{1} & Enhalus acoroides & 11,55 & 0 & 14,21 & 13,45 \\
2 & Thalassia hemprichii & 0 & 12,5 & 0 & 1.89 \\
\hline \multicolumn{2}{c}{ Total } & 11,55 & 12,5 & 14,21 & 15,34 \\
\hline
\end{tabular}

Tabel 2. Fraksi Sedimen (\%) di Pulau Panjang dan Pulau Lima, Teluk Banten

\begin{tabular}{cccccccc}
\hline & \multicolumn{2}{c}{ Pulau Panjang } & \multicolumn{3}{c}{ Pulau Lima } \\
\hline \multirow{2}{*}{ Lokasi } & \multicolumn{2}{c}{ Fraksi Sedimen (\%) } & Lokasi & \multicolumn{2}{c}{ Fraksi Sedimen (\%) } \\
\cline { 2 - 7 } & Gravel & Sand & Silt & & Gravel & Sand & Silt \\
\hline Stasiun & $3,92-$ & $43,65-$ & $41,7-$ & Stasiun & $4,39-$ & $76,94-$ & $10,17-$ \\
1 & 5,43 & 54,38 & 50,92 & 1 & 7,84 & 81,99 & 18,44 \\
Stasiun & $1,46-$ & $86,88-$ & $5,63-8,37$ & Stasiun & $1,58-$ & $83,01-$ & $8,04-$ \\
2 & 4,74 & 92,91 & 5 & 8,96 & 86,93 & 11,49 \\
\hline
\end{tabular}

Tabel 3. Nilai Parameter Perairan di Pulau Panjang dan Pulau Lima, Teluk Banten

dan daerah yang ditumbuhi mangrove. Selain

\begin{tabular}{cccc}
\hline \multirow{2}{*}{ Parameter } & \multicolumn{2}{c}{ Lokasi } & \multirow{2}{*}{ Nilai Optimum } \\
\cline { 2 - 3 } & Pulau Panjang & Pulau Lima & \\
Suhu & $30,8-34,5$ & $32,3-32,8$ & $28,00-30,00$ ( Fredriksen et al., 2010) \\
Salinitas & $35,5-38$ & $35,5-38$ & $34-40$ ppt (Purvaja et al, 2018) \\
$(\mathrm{ppt})$ & 7,4 & 7,6 & $7-8,5$ ppt (Purvaja et al, 2018) \\
pH & $0,03-0,09$ & $0,01-0,02$ & 0,15 (Minerva et al., 2014) \\
$\begin{array}{c}\text { Kecepatan Arus (m/s) } \\
\text { Kedalaman }\end{array}$ & $82-94$ & $65-91$ & - \\
$(\mathrm{cm})$ & & & \\
\hline
\end{tabular}


jenis dan ukuran substrat, menyukai dan memiliki persebaran yang luas di daerah teluk itu, penelitian sebelumnya dari Yunitha et al. (2014), dapat menguatkan hasil komposisi sedimen di stasiun 1 bahwa sedimen yang lebih dekat dengan daerah mangrove kebanyakan sedimen jenis pasir berlempung yang disebabkan juga oleh fungsi ekologis ekosistem mangrove yaitu sebagai perangkap penangkap sedimen. Stasiun 1 Pulau Panjang memiliki sedimen yang paling halus dengan jenis sedimen pasir berlumpur. Sebagai pembanding, penelitian dari Latuconsina (2012), menjelaskan keberadaan lamun yaitu pada substrat pasir dan lumpur yang membentuk padang yang cukup luas, hal ini dikarenakan pada penelitian ini lokasinya berdekatan dengan muara sungai sebagai pemasok material sedimen dari daratan yang menyebabkan tingginya kandungan nutrien. Stasiun 2 Pulau Panjang hanya terdapat 1 jenis lamun yaitu Thalassia hemprichii dengan nilai hasil analisa ukuran butir yang dapat dikategorikan bahwa pada stasiun 2 Pulau Panjang jenis sedimennya adalah pasir dengan fraksi sand yang sangat tinggi dan mendominasi. Hasil jenis sedimen di stasiun 2 Pulau Panjang dapat dikuatkan dari penelitian sebelumnya yaitu menurut Latuconsina (2012), bahwa ditemukan lamun jenis Thalassia hemprichii yang didominansi dengan sedimen pasir ukuran sedang dan penelitian dari Yunitha et al. (2014), bahwa lamun jenis Thalassia hemprichii lebih mampu hidup dengan baik pada substrat pasir dengan diameter besar.

Hasil jenis sedimen di Pulau Lima ini dapat dikuatkan dari penelitian Purnawan (2015), bahwa lokasi padang lamun yaitu memiliki sedimen berjenis pasir Iumpuran (Silty Sand) dengan sedikit kerikil (gravel) dan penelitian dari Riniatsih (2016), bahwa lamun dengan jenis Enhalus acoroides dan Thalassia hemprichii lebih cenderung menyebar pada habitat yang memiliki substrat dasar pasir berlumpur.

\section{KESIMPULAN}

Kesimpulan dari penelitian ini yaitu lamun yang ditemukan yaitu jenis Enhalus acoroides dan Thalassia hemprichii dengan nilai tutupan di Pulau Panjang yaitu 11,55$12,5 \%$ dan di Pulau Lima yaitu 14,21-15,34\%. Kondisi ekosistem padang lamun di Pulau Panjang dan Pulau Lima masuk dalam kategori rusak yaitu nilai penutupan lamun $\leq 29,9 \%$. Terdapat 2 faktor lingkungan yang diukur diluar nilai optimum bagi pertumbuhan lamun yaitu suhu dan kecepatan arus dengan komposisi sedimen yang ditemukan yaitu berjenis pasir dan pasir berlumpur.

\section{REFERENSI}

Aryawati, R., Ulqodry, T., Surbakti, H. \& Ningsih, E., 2018, Populasi Fitoplankton Skeletonema di Estuaria Banyuasin, Sumatera Selatan, Jurnal IImu dan Teknlogoi Kelautan Tropis, 10(2): 269275.

Chamidy, A.N., Suryono, C.A. \& Riniatsih, I., 2020, Analisis Multivariat Untuk Melihat Hubungan Jenis Sedimen Terhadap Jenis Lamun, Journal of Marine Research. 9(1):94-98.

Fredriksen, S., de Backer, A., Bostrom, C. \& Christie, H. 2010, Infauna from Zostera marina L. Meadows in Norway, Differences in Vegetated and Unvegetated Areas, Marine Biology Resesearch, (9)6:189-200.

Keputusan Menteri Lingkungan Hidup Nomor 200 Tahun 2004.

Kiswara, W. 1992, Struktur Komunitas Padang Lamun Perairan Indonesia dalam Inventarisasi dan Evaluasi Potensi Laut Pesisir II, P3O-LIPI. Jakarta: 54-61.

Latuconsina, H, 2012, Sebaran Spasial Vegetasi Lamun (Sea Grass)

Berdasarkan Perbedaan Karakteristik Fisik Sedimen di Perairan Teluk Ambon Dalam, Jurnal Bimafika, 4(1):405-412.

Minerva, A., Purwanti, F. \& Suryanto, A., 2014. Analisis Hubungan Keberadaan dan Kelimpahan Lamun dengan Kualitas Air di Pulau Karimunjawa, Jepara, Diponegoro Journal of Maquares, 3(3):88-94.

Purnawan, S., 2015, Kajian Awal Granulometri pada Kawasan Lamun dan Terumbu Karang: Studi Kasus di Gugusan Pulau Pari, Kepulauan Seribu, Depik, 4(2): 107-114.

Purvaja, R., Robin, R.S., Ganguli, D., Hariharan, G., Singh, G., Raghuraman. R. \& Ramesh, R. 2018. Seagrass meadows as proxy for assessment of ecosystem health. Oceancoaman, 159:34-45

Rahmawati, S., Irawan, A., Supriyadi, I.H. \& Azkab, M.H., 2014, Panduan Monitoring Padang Lamun. Puslit Oseanografi LIPI. Jakarta.

Riniatsih, I., 2015, Distribusi Muatan Padatan Tersuspensi (MPT) di Padang Lamun di Perairan Teluk Awur dan Pantai Prawean Jepara, Jurnal Kelautan Tropis, 18(3): 121-126. 
Riniatsih, I., 2016, Distribusi Jenis Lamun Dihubungkan dengan Sebaran Nutrien Perairan di Padang Lamun Teluk Awur, Jepara, Jurnal Kelautan Tropis, 19(2): 101-107.

Supriyadi, I.H., Cappenberg, H.A., Souhuka, J., Makatipu, P.C. \& Hafizt, M 2018, Kondisi Terumbu Karang, Lamun dan Mangrove di Suaka Alam Perairan Kabupaten Raja Ampat Provinsi Papua Barat, Jurnal Penelitian Perikanan Indonesia, 23(4):241-252.

Saputra, H., Subardjo, P., \& Saputro, S., 2013, Studi Pola Sebaran Sedimen Dasar Akibat Arus Sepanjang Pantai di Sekitar Pemecah Gelombang Pantai Kuta Bali,
Jurnal Oseanografi, 2(2): 161-170.

Tangke, U., 2010, Ekosistem Padang Lamun (Manfaat, Fungsi, dan Rehabilitasi), Jurnal Ilmiah Agribisnis dan Perikanan, 3(1):43-52.

Waycott, M., Mc Mahon, K., Mellors, J., Calladine, A., \& Kleine, D. 2004, A Guide to Tropical Seagrasses of the Indo-West Pacific, James Cook University, Townsville (AU).

Yunitha, A., Wardiatno, Y. \& Yulianda, F. 2014, Diameter Substrat dan Jenis Lamun di Pesisir Bahoi Minahasa Utara: Sebuah Analisis Korelasi, Jurnal IImu Pertanian Indonesia, 19(3):130-135. 